\title{
Dialogia
}

\section{Encontro entre linguagens? Análise da apropriação pedagógica de filmes no Projeto "O Cinema vai à escola", segundo o olhar do professor de língua portuguesa*}

\author{
Encounter among languages? Analysis of the pedagogical appropriation of films in \\ the Project "O Cinema vai à escola", according to the teacher of portuguese \\ language \\ Humberto Perinelli Neto \\ Doutor em História, pela UNESP.
} Docente do Programa de Pós-Graduação em Ensino e Processos Formativos da UNESP, Ilha Solteira/Jaboticabal/São José do Rio Preto, SP - Brasil.

perinellineto@yahoo.com.br

Vanessa Freitas de Sousa

Licenciada em Letras, pela UNESP. Graduanda em Cinema e Audiovisual (bacharelado), pela UNESPAR srta-vanessa@hotmail.com

\begin{abstract}
Resumo: Trata-se de texto cujo objetivo é o de refletir sobre o Projeto "O Cinema vai à Escola", desenvolvido pela Secretaria de Educação do Estado de São Paulo, a partir de 2008, por meio da análise do seu material pedagógico ("Os Cadernos de Cinema do Professor", mais os trinta roteiros pedagógicos e as caixas de filmes), tendo em vista o que é esperado do professor dedicado a lecionar a disciplina Língua Portuguesa e com base em duas categorias: roteiro e gênero cinematográficos. A pesquisa apresentou abordagem qualitativa, natureza aplicada e conciliou descrição e explicação, valendo-se para isso de investigações bibliográficas e documentais.
\end{abstract}

Palavras-chave: Cinema e Educação; Ensino de Língua Portuguesa; Processos Formativos.

Abstract: It is a text whose objective is to reflect on the "O Cinema vai à Escola" Project, developed by the Secretariat of Education of the State of São Paulo, from 2008, through the analysis of its pedagogical material ("The Notebooks of the Cinema of the Teacher", thirty scripts and the boxes of films), in view of what is expected of the teacher dedicated to teaching the Portuguese Language discipline and based on two categories: screenplay and cinematographic genres. The research presented a qualitative approach, applied nature and reconciled description and explanation, making use of bibliographical and documentary investigations.

Keywords: Cinema and Education; Teaching of Portuguese Language; Formative Processes.

\section{Introdução}

A capacidade de provocar encantamento e de intervir na construção de visões de mundo gerou o desenvolvimento de várias experiências em torno do emprego de filmes em vários setores sociais, inclusive nas escolas brasileiras, desde as primeiras décadas do século XX e até os dias atuais. Conforme afirma Duarte e Alegria, quando o "cinematógrafo chegou 
ao Brasil, em 1895, a imagem já era considerada como um importante auxiliar do ensino" (2008, p. 62).

Foi nesse sentido, inclusive, que vários projetos foram criados e desenvolvidos para gerarem a apropriação de filmes na Educação Básica (MONTEIRO, 2006a; SALIBA, 2003; MOGADOURO, 2011; MOURA, 2013; SILVA, 2009).

Um projeto diferenciado nesse campo foi o Ceduc-vídeo, desenvolvido pela Fundação para o Desenvolvimento da Educação (FDE), no período de entre 1988 e 1997. Isso porque esse projeto foi pensado por e para educadores, matizado para a educação, o que significou: assumir a existência “[...] de um público-alvo bastante definido e também de um propósito bem claro: o enriquecimento cultural e cognitivo dos atores educacionais alunos e professores - e do processo de ensino e aprendizagem que ocorre na escola" (SILVA, 2009, p. 199).

Em 2014, para citar uma das últimas ações nesse sentido, o projeto de lei PL 185/08 foi retomado e deu origem ao Projeto de Lei 13.006, assinado pela presidente Dilma Rousseff, que torna obrigatória a exibição de duas horas mensais de filmes nacionais em todas as escolas brasileiras (FRESQUET, 2015).

Neste contexto, em 2008, outro projeto envolvendo cinema e educação foi implementado: "O Cinema vai à Escola" (doravante, tratado também como Projeto), junto à rede pública estadual paulista de educação. Ele remetia à prática do Currículo Oficial do Estado de São Paulo e visava facilitar o acesso do aluno a diferentes produções cinematográficas, ampliar seu repertório e ensiná-lo a ler os filmes e a entender o discurso cinematográfico.

Para a implementação do Projeto foram fornecidas às escolas de Ensino Médio “[...] um conjunto de filmes de diferentes categorias e gêneros, em DVD, acompanhado de materiais de apoio à prática pedagógica." (SÃO PAULO, S.D.B). Entende-se por materiais: seis caixas de filmes (totalizando 71 títulos), distribuídas ao longo dos anos. Constava ainda no material: um DVD pedagógico (“LUZ, CÂMERA... EDUCAÇÃO!”); quatro cadernos de apoio ao professor ("Caderno de Cinema do Professor") e alguns roteiros para o emprego dos filmes.

Devida sua relevância, "O Cinema vai à Escola" já foi objeto de alguns estudos (MOGADOURO, 2011; MOURA, 2013). Contudo, não se registrou pesquisa dedicada especificamente ao material de apoio do professor, quanto menos com enfoque em Língua Portuguesa. Tal ausência é sentida, se observarmos que a maior parte das sugestões de filmes 
(90\%) envolve, justamente, a área de Linguagens e Códigos, mais especificamente, a referida disciplina de Língua Portuguesa.

É nesse sentido que o objetivo deste trabalho consiste em refletir sobre o Projeto, por meio da análise do seu material pedagógico (“Os Cadernos de Cinema do Professor”, mais os trinta roteiros e as caixas de filmes), tendo em vista o que é esperado do professor dedicado a lecionar Língua Portuguesa e com base em duas categorias: roteiro e gênero cinematográficos.

O trabalho apresentou como fundamentação teórica autores como Maurice Tardif (2012) e Paulo Freire (2016), posto que destacam a necessidade da ação dos professores envolver materiais didáticos diversos, abertura para o novo, exercício da autonomia e de ser constituída a partir das necessidades pedagógicas reais.

A significância do cinema para o ensino dialoga também com Paulo Freire (2016) em decorrência da concepção de prática educativa progressista que defende. Nas palavras do próprio Freire:

[...] uma das tarefas precípuas da prática educativo-progressista é exatamente o desenvolvimento da curiosidade crítica, insatisfeita, indócil, Curiosidade com que podemos nos defender de 'irracionalismos' decorrentes do ou produzidos por certos excessos de 'racionalidade' de nosso tempo altamente tecnologizado (2016, p. 34).

A abordagem da relação entre cinema e ensino vai ao encontro das concepções de Maurice Tardif (2012) por conta também de a ênfase deste estudioso na existência de processo multifatorial envolvendo a construção do fazer docente, o que, na prática, implica na necessidade de se pensar nos saberes docentes (temporais, profissionais, curriculares, disciplinares e experienciais) para garantir melhor apropriação pedagógica dos filmes.

O referencial teórico igualmente envolveu contribuições de Duarte e Alegria (2008), Napolitano (2013) e Setton (2010), por refletirem sobre a capacidade de o cinema propiciar a construção epistemológica/estética/política do conhecimento, assim como assim como de identidades socioculturais e de imaginários.

A pesquisa proposta apresentou abordagem qualitativa, natureza aplicada e conciliou descrição e explicação, valendo-se para isso de investigações bibliográficas e documentais (GIL, 1994; 2007; MINAYO, 2000; TRIVINÕS, 1987; GAMBOA, 1997; ALVESMAZZOTTI, GEWANDSZNAJDER, 1999).

\section{Roteiro cinematográfico}


Segundo Martins (2015), o roteiro pode ser entendido como gênero intersemiótico: transição entre a linguagem verbal e a não verbal, cujo resultado é exclusivamente o filme. Para Carrière e Bonitzer (1996), roteiro é inicialmente "[...] a descrição mais ou menos precisa, coerente, sistemática, e se possível atraente e compreensível, de acontecimento ou de série de acontecimentos, quaisquer que eles sejam” (p. 83-84). No mesmo sentido, para Campos (2007) o roteiro "é o esboço de uma narrativa que será realizada através de imagens e sons numa tela de cinema ou tv" (p. 328).

Sobre a originalidade do roteiro, podemos assumir, conforme Carrière e Bonitzer, que:
A originalidade verdadeira não se deixa descobrir num primeiro olhar; resulta frequentemente de arranjos secretos, de deslocamentos algumas vezes imperceptíveis num esboço tradicional. O que Rohner sem dúvidas quer dizer é que a originalidade consiste em uma questão de escrita, de encenação - não existem histórias originais (1996, p. 88).

Um roteiro adaptado, por sua vez, é aquele que tem por base uma outra obra verbal ou não. Nesse sentido, entendemos adaptação como Monteiro:

[...] um discurso que se atualiza. Tomando como base o pensamento de Michel Foucault, podemos considerar a adaptação de um clássico da literatura como uma estratégia de atualização de um discurso literário [...] (2006b, p. 16).

Sobre a escolha da categoria, discutir roteiros original e adaptado nos parece pertinente, uma vez que o professor de Língua Portuguesa precisa trabalhar com adaptações. Aliás, espera-se justamente isso: que o aluno possa confrontar opiniões sobre as diferentes linguagens "e suas manifestações específicas" (BRASIL, 2000, p. 08). Ademais, "entende-se que também a linguagem não-verbal perpassa os conteúdos e temas da [...] disciplina” (Idem, p. 59).

No que concerne ao material disponibilizado pelo Projeto, quantitativamente, há um total de 25 roteiros adaptados (39\% do total da caixa), derivados dos seguintes discursos originais: dois teatros, doze romances, três romances autobiográficos, dois diários, uma fábula, uma novela, um conto; além de outros gêneros já midiáticos (um curta-metragem, um programa de TV e um jogo).

No que consiste às atividades sugeridas no material, percebemos que, apesar da mistura entre roteiros originais e adaptados, pouco se problematiza o assunto. As discussões sobre roteiros adaptados aparecem, quase sempre, como meros apontamentos.

A leitura do "Caderno de cinema do professor" permite comprovar o tratamento pontual da ideia de roteiro. Exemplo disso é o trecho: "Antes de iniciar a projeção, é 
importante informar aos alunos que o filme é uma adaptação da peça teatral de mesmo nome, do dramaturgo Dias Gomes, escrita em 1959.” (TOZZI et al, 2008, p. 84). Outra passagem é: "O filme é uma adaptação cinematográfica do romance homônimo de Ray Bradbury" (TOZZI et al, 2010, p. 26). Tem-se ainda na caixa três o seguinte enunciado: "O filme se baseia na obra homônima do romancista Charles Dickens” (TOZZI et al, 2009b, p. 02).

Identificamos duas formas de promover alguma discussão sobre roteiro adaptado no material do Projeto. Uma delas é baseada em critérios de fidelidade: "ele [o roteiro] não é uma adaptação muito fiel à obra literária. Um contato com o texto de Shelley possibilita uma boa discussão sobre a transposição desta para o cinema.” (TOZZI et al, 2008, p. 64). Outra é baseada no cotejo, não valorativo, de uma obra com a outra: "Os professores podem trabalhar a imagem fazendo as leituras formal e interpretativa da obra e ainda comentar sobre o livro A Invenção de Hugo Cabret, de Brian Selznick” (TOZZI et al, 2008, p. 04).

As duas formas podem ser entendidas como insuficientes para trabalhar o tema, afinal, a comparação entre elas não pode ser pautada exclusivamente nos critérios de (in) fidelidade. Ademais, se entendermos a questão da linguagem enquanto mídia, conforme Martins, temos a mudança do suporte físico para outro, assim:

\begin{abstract}
Ora, a questão da "fidelidade" "infidelidade", nesse caso, não se põe, ou não deveria se por, porque é impossível arbitrar o grau de fidelidade ou infidelidade ao longo desse processo de tradução/transposição intersemiótica, uma vez que as radicais diferenças entre os sistemas de signos nascem, necessariamente, dos diversos modos de representação que os decodificadores (leitores, roteiristas, diretores, produção técnica) têm do texto-fonte e de seu resultado final, que é a obra audiovisual (2015, p.133-134).
\end{abstract}

Nesse sentido, o trabalho com adaptação deveria ser entendido como possibilidade que "permite-nos fazer um apanhado das inúmeras semelhanças, bem como das divergências consideráveis que existem entre estas duas linguagens" (BETTON, 1987, p. 115), com o intuito de aprofundar nossos conhecimentos sobre as linguagens.

Desse modo, o professor de Língua Portuguesa deve estar preparado para trabalhar com as adaptações, não só porque "a transposição do texto literário para outras artes e outras mídias é algo corriqueiro em nossa cultura visual e verbal contemporânea" (MARTINS, 2015, p. 131), mas também porque o cinema tem se apoiado cada vez mais nesse tipo de texto.

No que tange aos roteiros originais, é preciso pensá-los enquanto gêneros intersemióticos, conforme definição mencionada anteriormente. Contudo, isso não significa enquadrá-lo aos gêneros literários (MARTINS, 2015). Aliás, mais interessante do que 
encaixá-los em determinado gênero, seria problematizá-los com os alunos. Nesse sentido, não incluir esse tipo de discussão como sugestão ao professor impede, em dada medida, que ela seja refletida e pensada na sala de aula.

No Projeto "O Cinema vai à Escola", o roteiro é tratado, na maioria das vezes, no tópico Curiosidades. O único apontamento significativo que encontramos foi:

O roteiro de um filme pode ser entendido como "esboço de uma narrativa que será realizada através de imagens e sons numa tela de cinema ou TV"1. Assim, nesse exercício, sugerimos um trabalho para explorar a estrutura do filme e entender como se desenvolve sua narrativa, como a fábula é construída e esboçada por meio de seu roteiro (TOZZI et al, 2010, p.74).

Não negamos que esta atividade possa ser enriquecedora e articulada, oportunizando refletir sobre a linguagem cinematográfica. No entanto, não entendemos o porquê de ela não se manter também em outros roteiros de filmes. Além disso, se por meio dela podemos pensar os operadores da narrativa (tempo, espaço, personagens etc) no roteiro, não compreendemos os motivos de não serem trabalhados frequentemente.

Além dessa perspectiva, os roteiros e, posteriormente, os filmes podem ser entendidos como gênero discursivo, no qual a narração e a descrição se misturam (ALVES, 2014; TURNER, 1997). A partir dessa perspectiva, os filmes servem para analisar, interpretar e aplicar "os recursos expressivos das linguagens, relacionando textos com seus contextos, mediante a natureza, função, organização das manifestações, de acordo com as condições de produção e recepção" (BRASIL, 2002, p. 08).

\section{Gênero cinematográfico}

Por gênero, pode-se entender "um sistema de códigos, convenções e estilos visuais que possibilita ao público determinar rapidamente e com alguma complexidade o tipo de narrativa a que está assistindo" (TURNER, 1997, p. 88). No entanto, nem sempre os gêneros foram empregados, pois: o "conceito dos gêneros foi criado durante o estabelecimento do sistema de estúdios de Hollywood, no intuito de facilitar as decisões de produção e a comercialização dos filmes” (BERGAN, 2010, p. 07).

Partindo dos quatro grandes gêneros cinematográficos (Drama, Comédia, Suspense e Aventura - NAPOLITANO, 2013, p. 61-62), constatamos que o mais recorrente em todas as caixas do Projeto "O Cinema vai à Escola” é o Drama (32 dos 71 filmes). Reconhecemos que isso ocorre por ser o gênero mais reconhecido canonicamente, segundo Napolitano 
(2013), pois comporta conflitos éticos e existências, justamente, os temas mais recorrentes neste Projeto.

Sobre os demais gêneros abordados no Projeto, entendemos que o Documentário acaba sendo bastante empregado, por conta de ser entendido como filme associado à verdade, definição que despreza o fato de ser um gênero, portanto, de ser composto por “[...] um conjunto de regras de linguagem para a elaboração do roteiro, técnicas de filmagem, princípios de montagem e edição, ou seja, implica um conjunto de escolhas dos profissionais" (NAPOLITANO, 2013, p. 30).

Quanto ao Western, ao Terror, à Animação, à Ficção Científica, os entendemos como subgêneros. Além disso, cada um deles tem seu grau de popularidade e aceitação por parte do público. É nesse sentido que o Western é incorporado ao Projeto: “A força dos filmes de faroeste reside em sua longeva familiaridade com o imaginário popular e em seu conteúdo imagético” (BERGAN, 2010, p. 92).

Por fim, destacamos que, no Projeto, prevê-se reflexão sobre os gêneros cinematográficos, mas não de modo padrão e constante. Ora essa é proposta para que o professor a faça com os alunos, como em: "Caberia, inicialmente, investigar o conhecimento dos alunos sobre os gêneros dos filmes, para que eles possam identificar qual é o gênero predominante no filme Cantando na Chuva” (TOZZI et al, 2008, p. 38, grifos do autor). Em outros momentos, ela não aparece ou aparece no tópico Curiosidades:

Assim como Diários de Motocicleta, Cinema, Aspirinas e Urubus se encaixa dentro de um gênero muito apreciado pelos cineastas, o road movie, filme de estrada, em que os personagens estão em movimento entre um lugar e outro e, nesse deslocamento, a trama acontece (Idem, p. 41).

Essa reflexão aparece, quase sempre, atrelada à novo gênero ainda não abordado no Projeto. Além disso, essa ocorrência possibilitou-nos supor que não é esperado que os filmes e, consequentemente, os gêneros, sejam trabalhados de acordo com a ordem apresentada pelo material, ou seja, entendemos que os filmes podem ser trabalhados conforme as necessidades do público e a escolha do professor. Essa suposição é fortalecida por constar no material considerações feitas sobre o filme "Diário de Motocicleta", antes mesmo de que ele ser devidamente apresentado no próprio material. Dessa forma, ainda que a comparação entre filmes do mesmo gênero seja bastante positiva, a partir do caso citado, entendemos que ela só pode ser bem feita se o professor conhecer previamente os filmes em questão.

Ainda sobre a discussão dos gêneros, qualitativamente, ela aparece relacionada as atividades. Exemplo disso é: "com que outros filmes deste gênero os alunos já tiveram contato? Após fazer um diagnóstico coletivo, peça para eles indicarem quais as principais 
diferenças entre os elementos aterrorizantes do início do século XX e os atuais" (TOZZI et al, 2008, p.65). Outra situação é: "O que é um road movie? A quais outros filmes desse mesmo gênero eles já assistiram? Recomendamos a retomada de Diários de Motocicleta, enviado na primeira caixa de filmes" (TOZZI et al, 2010, p. 102).

A partir dos trechos selecionados, também pudemos notar que, embora "Diários de Motocicleta" seja entendido em outras fichas como road movie, na dele próprio, ele é tratado como Drama. Assim, ocorre mudança de perspectiva quanto ao gênero desse filme, o que é aceitável, uma vez que os gêneros se relacionam e, em dada medida, se misturam. Mas, nesse contexto, não há qualquer informação ou aviso aos professores sobre essa mudança ou sobre o fato de acontecer o imbricamento dos gêneros.

Se analisarmos o número de vezes em que aparecem outras discussões sobre os gêneros, teríamos doze em um total de sessenta e quatro roteiros. Assim, com base nesses dados, não negamos que haja tentativa de reflexão sobre os gêneros, mas registramos que ela não é voltada para a formação e a prática de professores. Aliás, sobre esse assunto, o único registro encontrado é o texto elaborado por Eduardo Morettin:

[...] western, por exemplo, é um dos mais duradouros gêneros da história do cinema americano. Da mesma forma que o melodrama e a comédia, sua genealogia é anterior ao advento do cinema e vincula-se a outros segmentos da cultura americana [...] (TOZZI et al., 2009a, p.59).

Percebemos que o texto de Morettin é sucinto, bem articulado e vai ao encontro dos objetivos traçados no "Caderno de Cinema do Professor: dois": "Rememorar a história do cinema e seus principais movimentos, gêneros e diretores e conhecer mais sobre o vasto mundo da linguagem cinematográfica" (CASTRO, 2009a, p. 05). Contudo, ele não é suficiente para promover as reflexões necessárias quanto à linguagem cinematográfica e sua apropriação pelos professores, porque pontual e um tanto quanto solto no conjunto de enunciados que formam os materiais do Projeto.

É preciso lembrar que a "classificação por gênero de estória está longe de seguir parâmetros nítidos" (CAMPOS, 2007, p. 65), ou seja, é preciso problematizar e discutir essa classificação, não apenas apontá-la como fixa. Sendo assim, a análise mais interessante poderia ser construída por meio da aproximação/comparação entre os gêneros fílmicos e gêneros literários (Lírica, Épica e Dramática).

Em vista disso, ao traçar paralelo entre os gêneros, a relação proposta poderia ser abordada a partir da diegese, ou seja, de acordo com o tempo das ações e o tipo de focalização, o que significaria atentar para o ponto de vista do narrador (CAMPOS, 2007). À vista disso, o "tempo verbal de uma narrativa é definido pela relação entre o tempo em que 
o narrador está e o tempo em que está a estória que ele narra" (CAMPOS, 2007, p. 70). Além disso, o modo de narrar se configura a partir das subjetividades:

[...] o narrador lírico as percebe e narra de dentro de si ou de um personagem, já o narrador épico as percebe e narra de fora do personagem e o dramático percebe e narra apenas as ações exteriorizadas a partir delas (CAMPOS, 2007, p. 77).

Ademais, os gêneros "[...] de narrativa se diferenciam uns dos outros não só pela forma como narram, mas também pelo conteúdo, pelos elementos que percebem e narram" (Idem, p. 79). Para tal, no caso do cinema, Campos aponta que em uma narrativa épica a voz over do narrador relataria o ocorrido, na lírica a voz off e as imagens, enquanto na dramática as imagens em si, já que os jogos de ações "são o ponto de foco principal” (2007, p.79).

No que consiste ao Projeto, reconhecemos algumas tentativas de aproximação de um gênero a outro. No entanto, essa comparação também acontece esporadicamente e, em alguns casos, sem relação. Como, por exemplo, em:

Por fim, pode-se pesquisar também como era a ficção científica na literatura antes do surgimento do cinema - com destaque para a obra de Júlio Verne - e depois da popularização dos filmes desse gênero (TOZZI et al, 2008, p. 62).

Nesse sentido, nossa crítica se mantém, justamente, por Júlio Verne não ser autor tipicamente trabalhado na escola. Aliás, não encontramos nenhum registro de sua obra no conteúdo de Ensino Médio e identificamos apenas duas menções sobre ele no Programa Nacional Biblioteca na Escola (PNBE), entre 2008 e 2013. Há, portanto, desencontro entre o que é trazido no "Caderno de Cinema do Professor" e o que é proposto no PNBE e, consequentemente, em relação aquilo que é trabalhado em sala de aula.

Por fim, cumpre questionar não só o lugar que é conferido aos gêneros cinematográficos, como também a articulação entre esses gêneros, ou ainda, entre os gêneros literários e os cinematográficos. Tanto para o primeiro questionamento quanto para o segundo falta formação para o professor de Língua Portuguesa, que, embora conheça a respeito dos gêneros literários, normalmente, não sabe muito sobre os gêneros fílmicos e, desse modo, não consegue tecer considerações ou fazer relação entre um e outro.

\section{Considerações finais}

Em síntese, podemos afirmar que o Projeto "Cinema vai à escola" tem suas qualidades e suas fraquezas. No entanto, conforme já apontamos, ele é essencial para o diálogo entre o cinema e o ensino, posto que após o Ceduc-vídeo, se tornou um dos projetos 
mais bem estruturado, no que diz respeito à elaboração de materiais, distribuição das caixas de filmes e dos cadernos e roteiros do Professor. Nesse sentido, juntamente com o Projeto de Lei 13.006/2014, esse projeto configura-se como caminho para que os filmes façam parte do cotidiano escolar.

A partir das categorias de análise, pudemos também perceber que as caixas, embora disformes com relação à quantidade de filmes, seguem um padrão. Em todas elas há roteiros originais e adaptados, embora o percentual dos primeiros corresponda a $61 \%$ do total de filmes. Do mesmo modo, nota-se que as caixas apresentam filmes que expressam gêneros diferentes, entretanto, predomina a opção por Dramas, tendo em vista se tratar de gênero oportuno para abordar problemas existenciais, sociais ou psicológicos e o projeto buscar, majoritariamente, o enfrentamento de temas como "pluralidade cultural", "ética" e "cidadania".

Várias são as possibilidades de promoção de práticas educativas de Língua Portuguesa com base no material do Projeto. A exploração das categorias roteiro e gênero cinematográficos são exemplos dessas possibilidades, uma vez que permitem reflexões sobre autoria, estilo, narrador, tempo, espaço, personagens, entre outros temas que favorecem o desenvolvimento da escrita e da leitura dos alunos. Os próprios responsáveis pelo Projeto parecem reconhecer essa relação com a Língua Portuguesa, visto que $90 \%$ dos filmes são sugeridos para a área de Linguagens e Códigos.

O grande desafio do "Cinema vai à escola" envolve a formação de professores. Da forma como é preparado o material (filmes, cadernos do professor e roteiros), exige-se do professor conhecimento cinematográfico que não é oportunizado nas formações iniciais e continuadas, tampouco é prevista no próprio Projeto.

O fato de o Projeto não contemplar formação continuada aos professores no campo cinematográfico aponta para limites na sua aplicação, bem como revela a perspectiva pedagógica que o baliza: trata-se do tecnicismo, velha marca de emprego do cinema no ensino brasileiro, responsável por fazer com que os filmes sejam apenas programados e exibidos, com base em manuais.

Avanços poderiam ser alcançados se o professor fosse pensado como educando, quando se trata do cinema. Na maioria das vezes, o professor não está preparado para lidar com filmes, visto que não teve essa formação. Daí pesquisas já realizadas sobre o projeto "Cinema vai à escola" (MOGADOURO, 2011; MOURA, 2013) indicarem que ele foi melhor desenvolvido, justamente, em escolas cujos professores apresentavam alguma formação e experiência envolvendo o cinema. 
Soma-se a isso, o reconhecimento de que o Projeto "Cinema vai à escola" precisa ser repensado a partir da posição que considera os filmes como obras dotadas de certa linguagem própria, acessíveis do ponto de vista epistemológico e estético, outrossim, distantes da visão que os tomam como meras ferramentas.

\section{Referências}

BERGAN, R. Ismos: para entender o cinema. São Paulo: Globo, 2010.

BETTON, G. Estética do cinema. São Paulo; Martins Fontes, 1987.

BRASIL. Secretaria da Educação Média e Tecnológica. PCN+: Ensino Médio: orientações educacionais complementares aos Parâmetros Curriculares Nacionais.

Brasília: MEC, 2002.

BRASIL. Secretaria de Educação Média e Tecnológica. Parâmetros Curriculares Nacionais (Ensino Médio). Brasília: MEC, 2000.

CAMPOS, F. Roteiro de Cinema e Televisão: A arte e a técnica de imaginar, perceber e narrar uma estória. Rio de Janeiro: Jorge Zahar Editor, 2007.

CARRIÈRE, J. C.; BONITZER, P., Prática do Roteiro Cinematográfico. São Paulo: JSN Editora, 1996.

CASTRO, M. H. G. de, Os possíveis diálogos do cinema e da educação. In: TOZZI, D. et al. (Org). Caderno do Cinema do Professor: dois, São Paulo, FDE, 2009, p.03.

DUARTE, R; ALEGRIA, A. Formação Estética Audiovisual: um outro olhar para o cinema a partir da educação. Educação \& Realidade, 33 (1): 59-80, jan./jun. 2008.

FREIRE, P. Pedagogia da autonomia: saberes necessários à prática educativa. Rio de Janeiro: Paz e Terra, 2016.

FRESQUET, A. (Org). Cinema e educação: A lei 13.006 - Reflexões, perspectivas e propostas. Belo Horizonte: Universo Produção, 2015.

MARTINS, R. A. F. Cinema e literatura: algumas reflexões e considerações sobre o roteiro como gênero intersemiótico. In: MARTINS, R. A. F; (org). Literatura, intersemiose, intermidialidade e transmidialidade. Jundiaí: Paco Editorial: 2015, p.09-28.

MOGADOURO, C. A. Educomunicação e escola: o cinema como mediação possível (desafios, práticas e proposta). Tese (Doutorado) - USP, 2011.

MONTEIRO, A. N. O Cinema Educativo como Inovação Pedagógica na Escola Primária Paulista (1933-1944). Dissertação (Mestrado) - USP, 2006a.

MONTEIRO, M. F. B. Permanência e Mutações: o desafio de escrever adaptações escolares baseadas em clássicos da literatura. Tese (Doutorado) - PUC/RJ, 2006b. 
MORETTIN, E. Uma história do cinema: movimentos, gêneros e diretores. In: TOZZI, D. et al. Caderno de cinema do professor: dois. São Paulo: FDE, 2009a, p.46-71.

MOURA, M. R. L. O cinema como prática educativa no ensino médio: Projeto "O Cinema vai à escola". Tese (Doutorado) - UFSCar, 2013.

NAPOLITANO, M. Como usar o cinema na sala de aula. São Paulo: Contexto, 2013. em:<http://portacurtas.org.br/faq/categoria.aspx?ifaq=6>. Acesso: 04 ag. 2018.

SALIBA, M. E. F. Cinema contra cinema: o cinema educativo de Canuto Mendes (1922-1931). São Paulo: Annablume: Fapesp, 2003.

SÃO PAULO. Secretaria de Estado da Educação. O Cinema vai à Escola. S.D.B Disponível em: http://culturaecurriculo.fde.sp.gov.br/Cinema/Cinema.aspx?menu=13\&projeto=3 > . Acesso em: 14 ago. 2018.

SETTTON, M. G. J. Mídia e educaşão. São Paulo: Contexto, 2010.

SILVA, A. C. V. Uma videoteca para a educação: O projeto Ceduc-vídeo, a Videoteca Pedagógica e as publicações sobre cinema e educação produzidas na Fundação para o Desenvolvimento da Educação - FDE entre 1988 e 1997. Dissertação (Mestrado) - USP, 2009.

TARDIF, M. Saberes docentes e formação profissional. Petrópolis: Vozes, 2012.

TOZZI, D. et al. Caderno de cinema do professor: dois. São Paulo: FDE, 2009a.

TOZZI, D. et al. Caderno de cinema do professor: um. São Paulo: FDE, 2008.

TOZZI, D. et al. Caderno de cinema do professor: quatro. São Paulo: FDE, 2010.

TOZZI, D. et al. Caderno de cinema do professor: três. São Paulo: FDE, 2009b.

TURNER, G. Cinema como prática social. São Paulo: Summus, 1997.

\section{Notas}

* Texto derivado do Projeto "Ensino em tela de cinema: estudo dos "Cadernos de Cinema do professor", projeto "O cinema vai à escola"/Secretaria da Educação do Estado de São Paulo", financiado pelo CNPq.

Recebido em: 07 set. 2018 / Aprovado em: 05 jun. 2019

\section{$\underline{\text { Cite como }}$}

PERINELLI NETO, Humberto; SOUZA, Vanessa Freitas de. Encontro entre linguagens? Análise da apropriação pedagógica de filmes no Projeto "O Cinema vai à escola", segundo o olhar do professor de língua portuguesa. Dialogia, São Paulo, n. 32, p. 210-221, maio/ago. 2019. Disponível em: https:// doi.org/10.5585/Dialogia.n32.10473. 